\title{
Effective desalination of acid mine drainage using an advanced oxidation process
}

\author{
Alexis Munyengabe ${ }^{\mathrm{a}}$, Caliphs Zvinowanda ${ }^{\mathrm{a}}$, John N. Zvimba ${ }^{\mathrm{b}}$, James Ramontja ${ }^{\mathrm{a}}$ \\ ${ }^{\mathrm{a}}$ University of Johannesburg, Faculty of Science, Doornfontein Campus, Department of Chemical Sciences, Corner Nind and Beit Streets, P O Box 17011, \\ Johannesburg, South Africa, 2028 \\ ${ }^{\mathrm{b}}$ Water Use and Waste Management, Water Research Commission, Bloukrans Building, Lynnwood Bridge Office Park, 4 Daventry Street, Lynnwood Manor, \\ South Africa.
}

\begin{abstract}
The screening and treatment of acid mine drainage (AMD) using $\mathrm{Na}_{2} \mathrm{FeO}_{4}$ has been explored. Elemental composition was performed using an ICP-OES for the raw and treated AMD. The AMD samples were collected from three different sampling sites (RTW1, RTW2 and RTW3) in Pretoria, South Africa with acidic pH ranging between 2.50 and 3.13. Total dissolved solids and Electrical Conductivity of AMD samples ranged between 960 and $>1000$ mg. L ${ }^{-1}, 226$ and $263 \mu \mathrm{S} . \mathrm{cm}^{-1}$, respectively. The final pH of treated water samples increased up to $\geq 9.5$ after treatment with $\mathrm{Na}_{2} \mathrm{FeO} 4$. Sodium ferrate showed dual functions by removing metals and raising the $\mathrm{pH}$ of the treated water. Concentrations of most trace elements were not complying with WHO and DWAF guideline standards in raw AMD while after treatment with $\mathrm{Na}_{2} \mathrm{FeO}_{4}$ the concentrations were below guidelines for domestic and irrigation purposes.
\end{abstract}

Keywords: Sodium ferrate (VI); Oxidation and Coagulation; Neutralization of AMD; Metal removal

\section{INTRODUCTION}

Acid mine drainage (AMD) is generated when mining wastewaters get in contact with oxygenated water. This AMD severely impacts the ecosystem through the leaching process of heavy metals, free acids and sulphate into ground and surface water (Younger, 2002). AMD also continues long after mining activities have stopped, and the consequences can last indefinitely followed by high clean-up costs. In some situations, it is not possible to perform its remediation with recent technologies. However, abandoned mine drainage seems to be a global environmental issue (Strosnider et al., 2014; Sun et al., 2013). The most known effective methods for AMD treatment are passive and active. The passive method employs unprocessed materials such as compost and limestone under gravity flow conditions in engineered basins including wetlands, limestone beds, ponds, and bioreactors. The active method employs dosage using chemicals such as alkali and alkaline earth metal hydroxides and oxidants (salts), and ongoing energy input for mixing and aeration in conventional wastewater treatment unit process (Goodwill et al., 2016). A hybrid system also exists that combines both passive and active approaches within the same treatment unit to remove trace and heavy metals. However, a quick abiotic Mn removal requires $\mathrm{pH}>9$, which is not achievable in a passive treatment and relatively expensive in an active treatment (Skousen et al., 2017; Goodwill et al., 2016). Therefore, the abiotic oxidation of reduced Mn is a common concern in AMD treatment, both from active and passive perspectives. A spontaneous removal of $\mathrm{Fe}$ and $\mathrm{Al}$ through oxidation of $\mathrm{Fe}$ and precipitation of metal hydroxides is relatively a straightforward process. Ferrate ion $\left(\mathrm{FeO}_{4}{ }^{2-}\right)$ is a coagulant and oxidant of increasing interest in

\footnotetext{
${ }^{1}$ Corresponding author: czvinowanda@uj.ac.za
} 
environmental studies (Sharma et al., 2016; Goodwill et al., 2016; Munyengabe, \& Zvinowanda, 2019), that can have advantages in AMD treatment. For instance, $\mathrm{FeO}_{4}{ }^{2-}$ presents a high oxidation potential $(+2.20 \mathrm{~V})$ in an acidic medium (Sharma et al., 2016), quickly oxidizes Mn and implies to the in-situ generation of ferric hydroxides that may support the coagulation process (Lv et al., 2018; Zheng, \& Deng, 2016; Goodwill et al., 2016). The $\mathrm{FeO}_{4}{ }^{2-}$ has also been indicated to not directly generate halogenated by-products in common natural water ways (Huang et al., 2016; DeLuca et al., 1983). There are three known procedures for preparing different ferrate salts. Firstly, ferrate (VI) ion can be synthesized through electrochemical technique using an iron-based anode in a strongly alkaline medium (Alsheyab et al., 2009; Dubrawski et al., 2018; Stanford et al., 2010). Secondly, ferrate (VI) salt can be synthesized through a wet oxidation method, which integrates the oxidation of iron sources such as ferric chloride or ferrous sulphate by hypochlorite $\left(\mathrm{OCl}^{-}\right)$ions in an alkaline solution (Ockerman, \& Schreyer, 1951; Munyengabe, \& Zvinowanda, 2019). Lastly, it can be produced using dry oxidation or thermal method (Lei et al., 2013) or solid-phase reaction method at a room temperature (Kooti, Jorfi, \& Javadi, 2010). To the best of our knowledge, there has not been a direct examination of the effectiveness of $\mathrm{FeO}_{4}{ }^{2-}$ ions for the treatment of AMD. Most prior and preliminary works have focused on ferrate applications in wastewater (Yates et al., 2014; Lee et al., 2009; Waite, \& Gray, 1984), drinking water (Sharma, 2002; Nguema, \& Jun, 2016; Song et al., 2016; Goodwill et al., 2016), oxidation of mine tailing and preventing acid drainage from uranium mill tailings (Fernandes et al., 2008), preliminary studies of ferrate treatment of metals in AMD (Goodwill et al., 2019), and TOC removal of surface water using ferrate (VI) (Momtazpour et al., 2019). However, thid study aimed at conducting a preliminary treatment of synthetic AMD using ferrate (VI) salt prepared through a wet oxidation method, assessment of metal concentrations in real AMD samples and their removal using sodium ferrate (VI) $\left(\mathrm{Na}_{2} \mathrm{FeO}_{4}\right)$ without using energy.

\section{METHODOLOGY}

\subsection{Water sampling process and guidelines}

Water samples were taken from three sampling locations (RTW1, RTW2 and RTW3), where RTW1: Raw Tailing Water sampling site 1, RTW2: Raw Tailing Water sampling site 2 and RTW3: Raw Tailing Water sampling site 3 located in Princess Goldmine Dump, Johannesburg. Princess Goldmine Dump is located in the southwest and west of Johannesburg, Gauteng Province in South Africa. The gold is contained within the conglomerates of the Witwatersrand Supergroup and the gold-bearing reefs also contain minerals such as pyrite, traces of silver, and other metals (Weissenstein, \& Sinkala, 2011). Clear pictures showing anthropogenic activities occurring in these sampling site areas are indicated in Figure 1. 


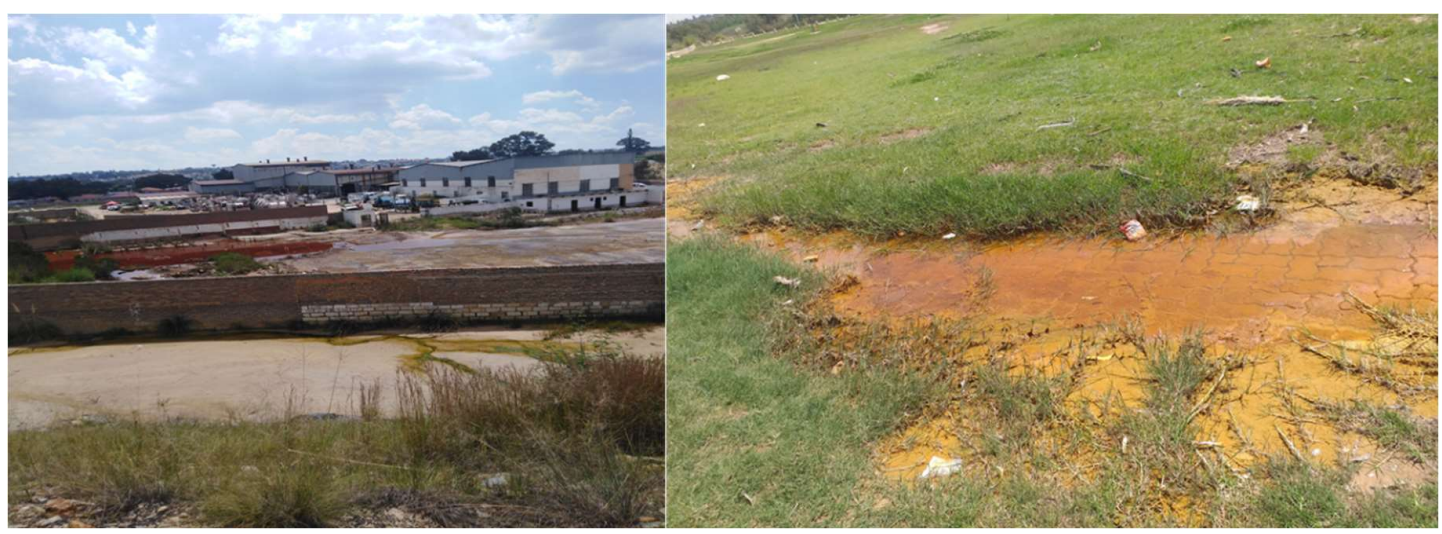

Figure 1: Environmental problems caused by Princess Goldmine Dump (to human settlement, factory, and Manuel Street Park)

At least three water samples were collected from the above-mentioned sampling sites and kept in 500 $\mathrm{mL}$ bottles. After the sampling process, some physical parameters of water such as temperature, TDS, $\mathrm{EC}$, and $\mathrm{pH}$ were immediately recorded. The samples were then transferred to the laboratory in a cooler box and kept in the refrigerator at $4{ }^{\circ} \mathrm{C}$ after the addition of $2 \mathrm{~mL}$ of concentrated $\mathrm{HNO}_{3}$. The $\mathrm{pH}$ values recorded from three sampling sites varied between 2.50 and 3.13 (Table 1) and were below the South African National Standards (SANS) 241:2015 and pH guidelines for drinking water compiled by World Health Organization (WHO). Bioavailability and speciation of metals in environmental matrices highly depend on physical parameters especially the $\mathrm{pH}$ of water. The $\mathrm{pH}$ values less than 4 generally increase the toxicity of most metals through the dissolution process. Electrical conductivity values of water samples were exceeding SANS 241-2015 and lower than the WHO guidelines. TDS of water collected from RTW2 were fitting into SANS241:2015 guidelines while there are no WHO guidelines for TDS for drinking water as shown in Table 1.

Table 1: Average levels of physical parameters in pond and tailing effluents

\begin{tabular}{ccccc}
\hline $\begin{array}{c}\text { Samples \& } \\
\text { Guidelines }\end{array}$ & $\begin{array}{c}\text { Temperature } \\
{ }^{\circ} \mathrm{C}\end{array}$ & $\begin{array}{c}\mathrm{pH} \\
\text { @ } 25^{\circ} \mathrm{C}\end{array}$ & $\begin{array}{c}\mathrm{EC} \\
\mu \mathrm{S} . \mathrm{cm}^{-1}\end{array}$ & $\begin{array}{c}\text { TDS } \\
\left(\mathrm{mg}^{-1} \mathrm{~L}^{-1}\right)\end{array}$ \\
\hline RTW1 & 26.2 & 2.58 & 262 & $>1000$ \\
RTW2 & 26.7 & 2.50 & 263 & 960 \\
RTW3 & 25.0 & 3.13 & 226 & $>1000$ \\
\hline SANS guidelines & $<30$ & $\geq 5$ to $\leq 9.7$ & $\leq 170$ & $\leq 1200$ \\
WHO guidelines & - & $6.5-9.5$ & 600 & - \\
\hline
\end{tabular}

The discussion of the results was performed concerning the current South African National Standards (SANS) (SANS 241, 2015) and WHO guidelines of drinking water (WHO, 2017) presented in Table 2. 
Table 2: SANS 241-2015 and WHO guidelines of drinking water

\begin{tabular}{ccc}
\hline Elements & $\begin{array}{c}\text { SANS 241-2015 (Limits for } \\
\text { drinkability) }\end{array}$ & $\begin{array}{c}\text { WHO guidelines (2017) } \\
\left(\mathrm{mg} . \mathrm{L}^{-1}\right)\end{array}$ \\
\hline $\mathrm{Al}$ & $\left(\mu \mathrm{g} . \mathrm{L}^{-1}\right)$ & \\
$\mathrm{Ca}$ & $\leq 300$ & 0.2 \\
$\mathrm{Cd}$ & - & $100-300$ \\
$\mathrm{Co}$ & $\leq 3$ & 0.003 \\
$\mathrm{Cr}$ & - & - \\
$\mathrm{Cu}$ & $\leq 50$ & 0.05 \\
$\mathrm{Fe}$ & $\leq 2000$ & - \\
$\mathrm{Mg}$ & $\leq 2000$ & $0.5-50$ \\
$\mathrm{Mn}$ & - & - \\
$\mathrm{Na}$ & $\leq 400$ & 0.4 \\
$\mathrm{Ni}$ & $\leq 200$ & 200 \\
$\mathrm{~Pb}$ & $\leq 70$ & 0.07 \\
$\mathrm{Zn}$ & $\leq 10$ & 0.01 \\
& $\leq 5$ & $<3$ \\
\hline
\end{tabular}

\subsection{Chemicals and reagents}

Liquid chemicals (AR grades); sodium hypochlorite $\left(15 \% \mathrm{~m} / \mathrm{v}\right.$ as $\left.\mathrm{Cl}_{2}\right), \mathrm{NaOH}(47 \% \mathrm{~m} / \mathrm{m})$ and ferric chloride $(43 \% \mathrm{~m} / \mathrm{m})$ were purchased from NCP Chlorchem Pvt. Ltd., South Africa and used without further purification. Ferrate salt standard (containing $\mathrm{FeO}_{4}{ }^{2-}$ ions) was ordered from American Elements Company, USA.

\subsection{Preparation of liquid sodium ferrate (VI)}

Liquid $\mathrm{Na}_{2} \mathrm{FeO}_{4}$ was produced using the wet oxidation method developed by Thompson et al. (1951) and Ockerman, \& Schreyer (1951) with some modifications. This method was selected because dry oxidation and electrochemical methods (El Maghraoui et al., 2013; El Maghraoui, Zerouale, \& Ijjaali, 2015) presented some drawbacks in the previous studies due to complex reaction steps and safety concerns involved (Bouzek, Schmidt, \& Wragg, 1999; Sharma, 2015). Hence, the modifications were performed to check if $\mathrm{Na}_{2} \mathrm{FeO}_{4}$ could be generated using only liquid reagents, to enhance the yield and stability of the product. Some optimum conditions developed by Sun et al. (2013) for preparing the liquid $\mathrm{Na}_{2} \mathrm{FeO}_{4}$ were also revised and considered in this study. The mixing proportions of the reagents were 10:5:1 (v:v:v) for $\mathrm{NaOCl}_{(\mathrm{aq})}, \mathrm{NaOH}_{(\mathrm{aq})}$ and $\mathrm{FeCl}_{3(\mathrm{aq})}$, respectively. An amount of $60 \mathrm{~mL}$ of $\mathrm{NaOCl}_{(\mathrm{aq})}$ and $30 \mathrm{~mL}$ of $\mathrm{NaOH}_{(\mathrm{aq})}$ was mixed into a $100 \mathrm{~mL}$ beaker placed in the ice bath and $6 \mathrm{~mL}$ of liquid $\mathrm{FeCl}_{3(\mathrm{aq})}$ was slowly added into the mixture with mild stirring. The ice batch was meant to quench the excess heat generated from an exothermic reaction, although the product is not stable at high temperatures. The mixture was gently heated at $25{ }^{\circ} \mathrm{C}$ for $10 \mathrm{~min}$ to speed up the reaction of the production of $\mathrm{Na}_{2} \mathrm{FeO}_{4}$. The low temperature was applied to avoid degradation of both hypochlorite 
ions and ferrate ions which were being produced. The basic chemical reaction for the preparation of $\mathrm{Na}_{2} \mathrm{FeO}_{4}$ (Sharma, Kazama, Jiangyong, \& Ray, 2005; Batarseh, Reinhart, \& Daly, 2007) is shown in Equation 1.

$2 \mathrm{FeCl}_{3(\mathrm{aq})}+3 \mathrm{NaOCl}_{(\mathrm{aq})}+10 \mathrm{NaOH}_{(\mathrm{aq})} \rightarrow 2 \mathrm{Na}_{2} \mathrm{FeO}_{4(\mathrm{aq})}+9 \mathrm{NaCl}_{(\mathrm{aq})}+5 \mathrm{H}_{2} \mathrm{O}_{(\mathrm{l})}$

The product obtained was exhibiting reddish-purple colour, which is very similar to the one obtained in the literature (Sun et al., 2013). The solution was centrifuged to remove impurities and the supernatant liquid was collected for further analysis. More details on its preparation, stability and characterization might be found in Munyengabe, \& Zvinowanda (2019).

\subsection{Optimization of parameters}

The optimum conditions followed during the treatment of real AMD are presented in Table 3 and more details could be found in Munyengabe et al. (2020).

Table 3: Optimum conditions obtained all parameters with initial and final $\left[\mathrm{Fe}^{2+}\right]$

\begin{tabular}{ccccc}
\hline $\begin{array}{c}\text { Time } \\
(\mathrm{min})\end{array}$ & $\mathrm{pH}$ & $\begin{array}{c}\text { Volume of } \mathrm{Fe}^{2+} \\
(\mathrm{mL})\end{array}$ & $\begin{array}{c}\text { Volume of ferrate } \\
(\mathrm{mL})\end{array}$ & $\begin{array}{c}{[\text { Ferrate }]} \\
\left(\mathrm{mmol} \mathrm{L}^{-1}\right)\end{array}$ \\
\hline 30 & 3.0 & 15 & 5 & $5 \times 10^{-2}$ \\
\hline
\end{tabular}

\subsection{Analytical techniques}

Inductively Coupled Plasma-Optical Emission Spectroscopy (ICP-OES) (iCap 6500 Duo, Thermo Scientific, UK) was used to determine metal concentrations in AMD before and after treatment with ferrate ions. Good linearity was obtained from the ICP-OES calibration curves of metals prepared from a multi-element $\left(100 \mathrm{mg}\right.$. $\left.\mathrm{L}^{-1}\right)$ standard solution. The main target elements to be removed in this study were $\mathrm{Fe}, \mathrm{Mn}$ and $\mathrm{Zn}$. Iron was selected during AMD treatment as it is the main cause of acidity in this type of water while $\mathrm{Mn}$ and $\mathrm{Zn}$ are hardly being removed from the water at a low $\mathrm{pH}$ value. Before the oxidation process, AMD was diluted 100 times by taking $1 \mathrm{~mL}$ of the sample into $99 \mathrm{~mL}$ of deionized water and filtered $(0.22 \mu \mathrm{m})$ to fit in the multi-element calibration curve ranging from 0 to $7.50 \mathrm{mg}$. $\mathrm{L}^{-}$

1. Treated AMD was first centrifuged, and the supernatant liquid was filtered using the same size of the filter. All samples were run three times on ICP-OES. Three untreated acidic water samples (RTW1, RTW2 and RTW3) were filtered and subjected to ICP-OES for screening purposes to assess the concentrations of metals, metalloids and trace elements. After that, a small portion $(20 \mathrm{~mL})$ from each AMD sample was treated with $5 \mathrm{~mL}\left(0.025 \mathrm{mmol} . \mathrm{L}^{-1}\right)$ of sodium ferrate (VI) in 30 minutes of contact time as optimum conditions. The removal percentage was calculated using the following Equation 2.

Removal percentage $=\left[\left(C_{i}-C_{r}\right) / C_{i}\right] \times 100 \%$ 
where, $C_{i}$ and $C_{r}$ are the initial and final concentrations (mg. $\left.\mathrm{L}^{-1}\right)$ of metals, respectively.

2.6 Flow diagram of real AMD treatment using sodium ferrate $\left(\mathrm{FeO}_{4}{ }^{2-}\right)$

This investigation aimed to demonstrate that ferrate treatment, offers an attractive solution to the treatment of AMD that is highly rich in $\mathrm{Fe}^{2+}$ and other dissolved metals as shown in Figure 2. The proposed flow diagram indicates all processes of AMD treatment where oxidation and chemical desalination processes were performed at $\mathrm{pH}=3$ during this study.

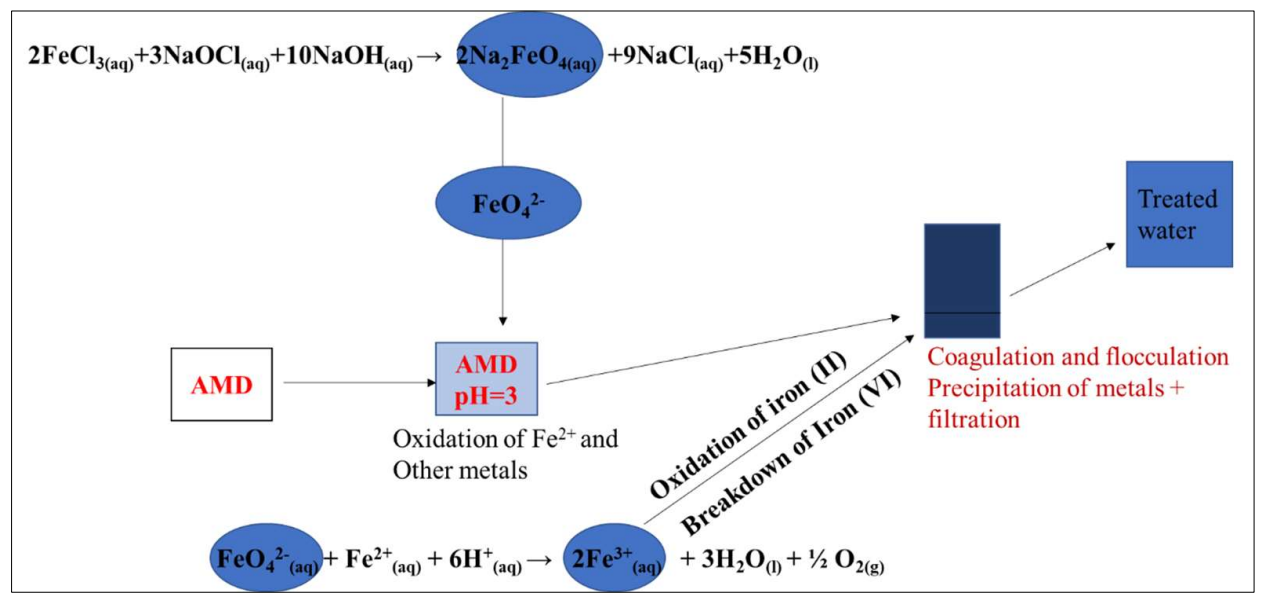

Figure 2: Process flow diagram of AMD treatment (oxidation and chemical desalination)

Figure 2 clearly shows the preparation of $\mathrm{Na}_{2} \mathrm{FeO}_{4}$, its implementation in the oxidation of $\mathrm{Fe}^{2+}$ in synthetic $\mathrm{AMD}$, and the production of $\mathrm{Fe}^{3+}$ from the self-decomposition of $\mathrm{FeO}_{4}{ }^{2-}$ ions as well as the oxidation of $\mathrm{Fe}^{2+}$ molar ratio (1:1) from AMD. These generated $\mathrm{Fe}^{3+}$ ions are common environmentally friendly coagulant providing the efficient adsorption and precipitation of different pollutants present in wastewater and water due to its high surface area.

\section{RESULTS AND DISCUSSIONS}

\subsection{Concentrations of metals in RTW1}

The initial and concentrations of all assessed metals in the raw AMD sample collected from RTW1 and their residual concentrations in the treated one by $\mathrm{Na}_{2} \mathrm{FeO}_{4}$ along with their percentage removals are presented in Table 4. 
Table 4: Sampling site RTW1

\begin{tabular}{cccc}
\hline Elements & $\begin{array}{c}\text { Initial concentrations } \\
\left(\mathrm{mg}^{-1}\right)\end{array}$ & $\begin{array}{c}\text { Residual concentrations } \\
\left(\mathrm{mg}^{-1} \mathrm{~L}^{-1}\right)\end{array}$ & \% Removal \\
\hline $\mathrm{Al}$ & $60.35 \pm 0.50$ & 15.77 & 73.90 \\
$\mathrm{Ca}$ & $36.66 \pm 0.00$ & 0.103 & 99.72 \\
$\mathrm{Cd}$ & $0.005 \pm 0.00$ & 0.004 & 26.00 \\
$\mathrm{Co}$ & $2.10 \pm 0.00$ & 0.0006 & 99.97 \\
$\mathrm{Cr}$ & $0.97 \pm 0.00$ & 0.370 & 61.72 \\
$\mathrm{Cu}$ & $4.74 \pm 0.00$ & 0.030 & 99.40 \\
$\mathrm{Fe}$ & $181.30 \pm 0.00$ & 0.540 & 99.70 \\
$\mathrm{Mg}$ & $28.53 \pm 0.00$ & 0.00 & 100.00 \\
$\mathrm{Mn}$ & $0.590 \pm 0.01$ & bdl & - \\
$\mathrm{Na}$ & $1.77 \pm 0.00$ & 0.00 & 100.00 \\
$\mathrm{Ni}$ & $4.87 \pm 0.01$ & 0.00 & 100.00 \\
$\mathrm{~Pb}$ & $0.002 \pm 0.00$ & bdl & - \\
$\mathrm{Zn}$ & $6.490 \pm 0.00$ & 0.280 & 95.70 \\
\hline
\end{tabular}

bdl: below the detection limit

This acidic water collected from RTW1 was highly characterized by $\mathrm{Fe}, \mathrm{Al}, \mathrm{Ca}$ and $\mathrm{Mg}$ while other metal concentrations were below $20.0 \mathrm{mg}$. $\mathrm{L}^{-1}$ as shown in Figure 3. The residual concentrations of most of the elements detected in RTW1 after being treated using sodium ferrate were below the WHO guidelines of drinking water (Table 3).

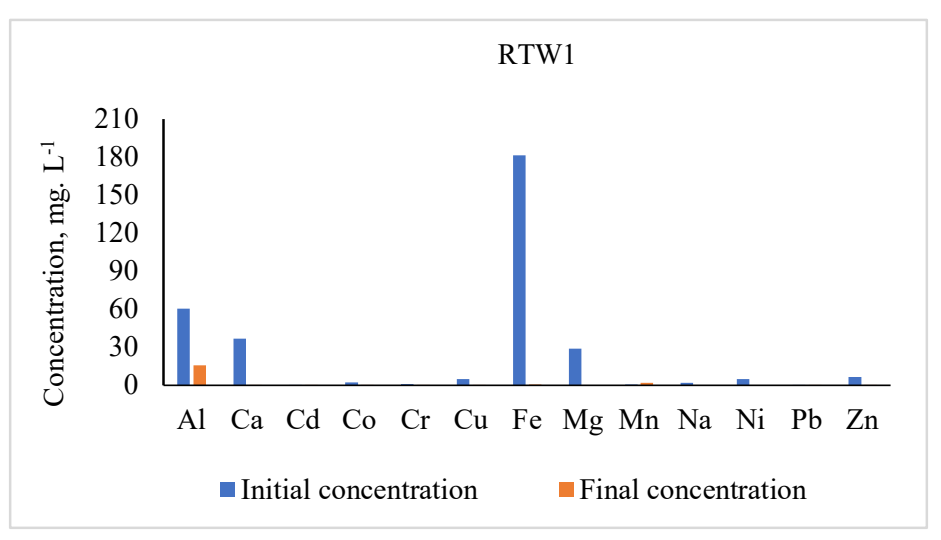

Figure 3: Initial and residual concentrations of metals in water collected from RTW1

The AMD sample also contained a high concentration of Cd which was greater than SANS 241-2015 for drinking water $\left(\leq 3 \mu \mathrm{g}\right.$. $\left.\mathrm{L}^{-1}\right)$ (Table 3). Therefore, the removal of all metals from $\mathrm{AMD}$ by $\mathrm{Na}_{2} \mathrm{FeO}_{4}$ ranged between 26 and $100 \%$. The low percentage removal for heavy metals especially Cd might be related to the acidic $\mathrm{pH}$ of the water and high TDS greater than $1000 \mathrm{mg}$. $\mathrm{L}^{-1}$. The previous study on $\mathrm{Cd}$ removal from natural water by $\mathrm{K}_{2} \mathrm{FeO}_{4}$ is highly $\mathrm{pH}$-dependent, where higher removal is related to higher $\mathrm{pH}$ values (Liang, Jun, \& Liu, 2007). 


\subsection{Concentrations of metals in RTW2}

The initial and residual concentrations of all assessed metals in the AMD sample collected from RTW2 are presented in Table 5.

Table 5: Sampling site RTW2

\begin{tabular}{cccc}
\hline Elements & $\begin{array}{c}\text { Initial concentrations } \\
\left(\mathrm{mg} . \mathrm{L}^{-1}\right)\end{array}$ & $\begin{array}{c}\text { Residual concentrations } \\
\left(\mathrm{mg} . \mathrm{L}^{-1}\right)\end{array}$ & \% Removal \\
\hline $\mathrm{Al}$ & $105.00 \pm 0.40$ & 16.560 & 84.23 \\
$\mathrm{Ca}$ & $\mathrm{bdl}$ & $\mathrm{bdl}$ & - \\
$\mathrm{Cd}$ & $\mathrm{bdl}$ & $\mathrm{bdl}$ & - \\
$\mathrm{Co}$ & $5.16 \pm 0.00$ & 0.011 & 99.78 \\
$\mathrm{Cr}$ & $1.02 \pm 0.00$ & 0.117 & 88.40 \\
$\mathrm{Cu}$ & $1.30 \pm 0.00$ & 0.007 & 99.45 \\
$\mathrm{Fe}$ & $521.40 \pm 0.05$ & 0.088 & 99.98 \\
$\mathrm{Mg}$ & $113.70 \pm 0.04$ & 0 & 100.00 \\
$\mathrm{Mn}$ & $15.48 \pm 0.01$ & 0.002 & 100.00 \\
$\mathrm{Na}$ & $47.07 \pm 0.04$ & 0.00 & 100.00 \\
$\mathrm{Ni}$ & $7.34 \pm 0.01$ & 0.00 & 100.00 \\
$\mathrm{~Pb}$ & $0.12 \pm 0.00$ & 0.001 & 98.85 \\
$\mathrm{Zn}$ & $10.75 \pm 0.00$ & 0.024 & 99.77 \\
\hline
\end{tabular}

This acidic water collected from RTW2 also contained high concentrations of $\mathrm{Fe}, \mathrm{Mg}$ and $\mathrm{Al}$ which were greater than $100 \mathrm{mg}$. $\mathrm{L}^{-1}$ while other metal concentrations were below $50 \mathrm{mg}^{-\mathrm{L}^{-1}}$ as shown in Figure 4.

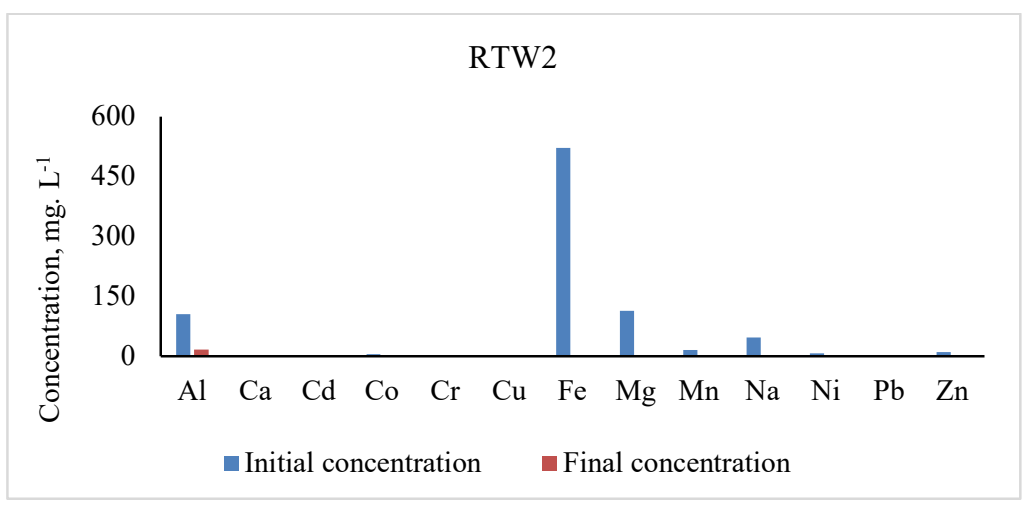

Figure 4: Initial and residual concentrations of metals in water collected from RTW2

Contrary to sampling site RTW1, Cd was not detected in this AMD sample, but Pd concentration was 12 times the SANS 241-2015 guidelines $\left(\leq 10 \mu \mathrm{g}\right.$. $\left.\mathrm{L}^{-1}\right)$. The initial concentration of $\mathrm{Cr}$ was also high than the SANS 241-2015 guidelines ( $\leq 50 \mu \mathrm{g}$. $\left.\mathrm{L}^{-1}\right)$ as presented in Table 3. Therefore, the removal of all metals from $\mathrm{AMD}$ by $\mathrm{Na}_{2} \mathrm{FeO}_{4}$ ranged between 84.23 and $100 \%$, which was better than the one found in the previous sampling site. 


\subsection{Concentrations of metals in RTW3}

The initial and residual concentrations of all assessed metals in the AMD sample collected from RTW3 are presented in Table 6.

Table 6: Sampling site RTW3

\begin{tabular}{cccc}
\hline Elements & $\begin{array}{c}\text { Initial concentrations } \\
\left(\mathrm{mg} . \mathrm{L}^{-1}\right)\end{array}$ & $\begin{array}{c}\text { Residual concentrations } \\
\left(\mathrm{mg} . \mathrm{L}^{-1}\right)\end{array}$ & \% Removal \\
\hline $\mathrm{Al}$ & $66.67 \pm 0.21$ & 9.321 & 86.02 \\
$\mathrm{Ca}$ & - & - & - \\
$\mathrm{Cd}$ & $0.003 \pm 0.00$ & 0.001 & 70.00 \\
$\mathrm{Co}$ & $1.929 \pm 0.00$ & 0.010 & 99.48 \\
$\mathrm{Cr}$ & $0.092 \pm 0.00$ & bdl & - \\
$\mathrm{Cu}$ & $1.159 \pm 0.00$ & 0.008 & 99.32 \\
$\mathrm{Fe}$ & $11.79 \pm 0.00$ & 0.017 & 99.85 \\
$\mathrm{Mg}$ & $104.30 \pm 0.03$ & 0 & 100.00 \\
$\mathrm{Mn}$ & $16.32 \pm 0.00$ & 0.002 & 99.98 \\
$\mathrm{Na}$ & $45.65 \pm 0.05$ & 0 & 100 \\
$\mathrm{Ni}$ & $1.949 \pm 0.00$ & bdl & - \\
$\mathrm{Pb}$ & $0.014 \pm 0.00$ & 0.002 & - \\
$\mathrm{Zn}$ & $3.374 \pm 0.00$ & 0.016 & 99.51 \\
\hline
\end{tabular}

This acidic water collected from RTW3 was also highly characterized by $\mathrm{pH}=3.13$ and high concentrations of alkali and alkaline earth metals; $\mathrm{Na}, \mathrm{Mg}$ and one metal such as $\mathrm{Al}$ which were greater than $40 \mathrm{mg}$. $\mathrm{L}^{-1}$ while other metal concentrations assessed were below $20 \mathrm{mg}$. $\mathrm{L}^{-1}$ including $\mathrm{Fe}$ as shown in Figure 5 .

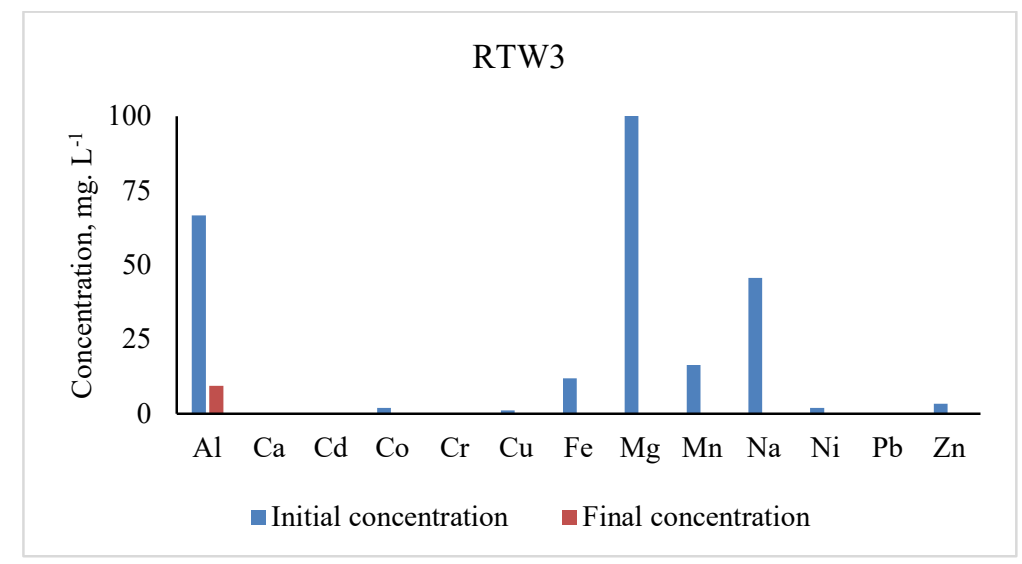

Figure 5: Initial and residual concentrations of metals in water collected from RTW3

The $\mathrm{pH}$ of AMD collected from sampling site RTW3 was greater than the other $\mathrm{pH}$ values observed in the previous sampling sites. This might be caused by the presence of $\mathrm{Na}, \mathrm{Mg}$ and $\mathrm{Al}$ in high concentrations. Both $\mathrm{Pd}\left(14.0 \mu \mathrm{g} . \mathrm{L}^{-1}\right)$ and $\mathrm{Cr}\left(92.0 \mu \mathrm{g}\right.$. $\left.\mathrm{L}^{-1}\right)$ were not meeting the SANS 241-2015 ( $\leq$ 
$10 \mu \mathrm{g} . \mathrm{L}^{-1}$ and $\leq 50 \mu \mathrm{g}$. $\mathrm{L}^{-1}$, respectively) (Table 3) before the treatment while Pd (2 $\left.\mu \mathrm{g} . \mathrm{L}^{-1}\right)$ met with the standards after treatment and $\mathrm{Cr}$ was below the detection limit. $\mathrm{Fe}$ as the main target element was completely removed with a removal efficiency of $99.85 \%$. In conclusion, sodium ferrate showed its potential of removing metals from raw tailing waters characterized with an acidic $\mathrm{pH}$ and the residual concentrations of most elements detected in all AMD samples were below the SANS 241-2015 and WHO guidelines (2017) of drinking water with a resultant $\mathrm{pH} \geq 9$. $\mathrm{Na}_{2} \mathrm{FeO}_{4}$ became the promising alternative material for water processing and mining wastewater with zero energy input and non-toxic by-products.

\section{CONCLUSIONS}

Liquid $\mathrm{Na}_{2} \mathrm{FeO}_{4}$ was quantitatively produced through a wet oxidation method. It was then applied for real AMD samples collected from three different places (RTW1, RTW2 and RTW3) in Johannesburg, Pretoria, South Africa, with corresponding $\mathrm{pH}$ values of 2.50, 2.58 and 3.13, respectively. The results demonstrated that $\mathrm{Na}_{2} \mathrm{FeO}_{4}$ has the potential to remove metals from AMD with percentage removal ranging between 26 and $100 \%$ for all sampling sites without generating harmful by-products. This showed that $\mathrm{Na}_{2} \mathrm{FeO}_{4}$ could become the promising alternative material for water processing and mining wastewater with zero energy input and non-toxic by-products. $\mathrm{Na}_{2} \mathrm{FeO}_{4}$ also played different roles such as oxidizer, coagulant, flocculent, and neutralizer where the resulting $\mathrm{pH}$ of treated AMD samples was greater than or equal to 9 .

\section{ACKNOWLEDGEMENTS}

This study was supported by the University of Johannesburg and NRF/South Africa. Many thanks to Prof P. N. Nomngongo, and the group members from Environmental Analytical Chemistry Lab 3404. Authors would like to acknowledge Ms V. N. Mukhethwa and Dr. M. Sihlahla for the provision of water samples and Dr D. Ramutshatsha for the assistance with ICP-OES.

\section{REFERENCES}

Alsheyab, M., Jiang, J. Q., \& Stanford, C. (2009). Online production of ferrate with an electrochemical method and its potential application for wastewater treatment: A review. Journal of Environmental Management, 90(3), 1350-1356. https://doi.org/10.1016/j.jenvman.2008.10.001

Batarseh, E. S., Reinhart, D. R., \& Daly, L. (2007). Liquid sodium ferrate and Fenton's reagent for treatment of mature landfill leachate. Journal of Environmental Engineering, 133(11), 1042-1050. https://doi.org/10.1061/(ASCE)0733-9372(2007)133:11(1042)

Bouzek, K., Schmidt, M. J., \& Wragg, A. A. (1999). Influence of electrolyte composition on current yield during ferrate (VI) production by anodic iron dissolution. Electrochemistry Communications, 1(9), 370-374. https://doi.org/10.1016/S1388-2481(99)00075-2

De Luca, S. J., Cantelli, M., \& De Luca, M. A. (1992). Ferrate vs traditional coagulants in the treatment of combined industrial wastes. Water Science and Technology, 26(9-11), 2077-2080. https://doi.org/10.2166/wst.1992.0665

Dubrawski, K. L., Cataldo, M., Dubrawski, Z., Mazumder, A., Wilkinson, D. P., \& Mohseni, M. (2018). In-situ electrochemical Fe (VI) for removal of microcystin-LR from drinking water: Comparing dosing of the ferrate ion by electrochemical and chemical means. Journal of Water and Health, 16(3), 414-424. https://doi.org/10.2166/wh.2018.187 
DWAF. (1996). South African Water Quality Guidelines, Vol. 7: Aquatic Ecosystems, $2^{\text {nd }}$ Ed.; Department of Water Affairs and Forestry: Pretoria, South Africa.

El Maghraoui, A., Zerouale, A., \& Ijjaali, M. (2015). Process for the synthesis of ferrate (VI) Alkali metal dry. Advances in Materials Physics and Chemistry, 5(01), 10. http://www.scirp.org/journal/PaperInformation.aspx?PaperID=53023\&\#abstract

El Maghraoui, A., Zerouale, A., Ijjaali, M., \& Sajieddine, M. (2013). Synthesis and characterization of ferrate (VI) alkali metal by electrochemical method. Advances in Materials Physics and Chemistry, 3(1), 83-87. http://www.scirp.org/journal/PaperInformation.aspx?PaperID=29310

Fernandes, H. M., Reinhart, D., \& Franklin, M. R. (2008). Use of Na-Ferrate (VI) to prevent acid drainage from uranium mill tailings. In Uranium, Mining and Hydrogeology (pp. 261-270). Springer, Berlin, Heidelberg. https://doi.org/10.1007/978-3-540-87746-2_35

Goodwill, J. E., LaBar, J., Slovikosky, D., \& Strosnider, W. H. (2019). Preliminary assessment of ferrate treatment of metals in acid mine drainage. Journal of Environmental Quality, 48(5), 1549-1556. https://doi.org/10.2134/jeq2019.02.0079

Goodwill, J. E., Mai, X., Jiang, Y., Reckhow, D. A., \& Tobiason, J. E. (2016). Oxidation of manganese (II) with ferrate: stoichiometry, kinetics, products and impact of organic carbon. Chemosphere, 159, 457-464. https://doi.org/10.1016/j.chemosphere.2016.06.014

Huang, X., Deng, Y., Liu, S., Song, Y., Li, N., \& Zhou, J. (2016). Formation of bromate during ferrate (VI) oxidation of bromide in water. Chemosphere, 155, 528-533. https://doi.org/10.1016/j.chemosphere.2016.04.093

Kooti, M., Jorfi, M., \& Javadi, H. (2010). Rapid chemical synthesis of four ferrate (VI) compounds. Journal of the Iranian Chemical Society, 7(4), 814-819. https://doi.org/10.1007/BF03246073

Lee, Y., Zimmermann, S. G., Kieu, A. T., \& von Gunten, U. (2009). Ferrate (Fe (VI)) application for municipal wastewater treatment: a novel process for simultaneous micropollutant oxidation and phosphate removal. Environmental Science and Technology, 43(10), 38313838. https://doi.org/10.1021/es803588k

Lei, B., Zhou, G., Cheng, T., \& Du, J. (2013). Synthesis of potassium ferrate by chemical dry oxidation and its properties in the degradation of methyl orange. Asian Journal of Chemistry, 25(1), 27. https://doi.org/10.14233/ajchem.2013.11685

Liang, Y. M., Jun, M., \& Liu, W. (2007). Enhanced removal of lead (II) and cadmium (II) from water in alum coagulation by ferrate (VI) pretreatment. Water Environment Research, 79(12), 2420-2426. https://doi.org/10.2175/106143007X212148

Lv, D., Zheng, L., Zhang, H., \& Deng, Y. (2018). Coagulation of colloidal particles with ferrate (VI). Environmental Science: Water Research and Technology, 4(5), 701-710. https://doi.org/10.1039/C8EW00048D

Munyengabe, A., \& Zvinowanda, C. (2019). Synthesis and chemical stability studies of sodium ferrate (VI) solution. Asian Journal of Chemistry, 31 (12), 3029-3034. https://doi.org/10.14233/ajchem.2019.22267

Munyengabe, A., \& Zvinowanda, C. Production, Characterization and Application of Ferrate (VI) in Water and Wastewater Treatments.

Munyengabe, A., Zvinowanda, C., Zvimba, J. N., \& Ramontja, J. (2020). Innovative oxidation and kinetic studies of ferrous ion by sodium ferrate (VI) and simultaneous removal of metals from a synthetic acid mine drainage. Physics and Chemistry of the Earth, Parts $A / B / C, 102932$.

Momtazpour, H., Jorfi, S., Tabatabaie, T., \& Pazira, A. A. (2019). Application of sodium ferrate produced from industrial wastes for TOC removal of surface water. Water Science and Technology, 79(7), 1263-1275. https://doi.org/10.2166/wst.2019.127

Nguema, P. F., \& Jun, M. (2016). Application of ferrate (VI) as a disinfectant in drinking water treatment processes: A review. International Journal, 7(2), 53-62. https://doi.org/10.5829/idosi.ijmr.2016.53.62

Ockerman, L. T., \& Schreyer, J. M. (1951). Preparation of sodium ferrate (VI). Journal of the American Chemical Society, 73(11), 5478-5478. https://doi.org/10.1021/ja01155a545

SANS (South African National Standards) 241:2015. (2015). Drinking-Water. Available online at https://selectech.co.za/whatyoushouldknowaboutthenew2015bluedroplimitssans2412015drinkingwater/\#: :text=The\%20new\%2 0SANS\%2041\%3A2015,afe20for\%20us\%20to\%20drink. Accessed on the $8^{\text {th }}$ August 2020.

Sharma, V. K. (2015). U.S. Patent No. 8,961,921. Washington, DC: U.S. Patent and Trademark office.

Sharma, V. K., Kazama, F., Jiangyong, H., \& Ray, A. K. (2005). Ferrates (iron (VI) and iron (V)): environmentally friendly oxidants and disinfectants. Journal of Water and Health, 3(1), 45-58. https://doi.org/10.2166/wh.2005.0005

Skousen, J., Zipper, C. E., Rose, A., Ziemkiewicz, P. F., Nairn, R., McDonald, L. M., \& Kleinmann, R. L. (2017). Review of passive systems for acid mine drainage treatment. Mine Water and the Environment, 36(1), 133-153. https://doi.org/10.1007/s10230-016-0417-1

Song, Y. R., \& Ma, J. W. (2013). Development of ferrate (VI) salt as an oxidant and coagulant for water and wastewater treatment. In Applied Mechanics and Materials (Vol. 361, pp. 658-661). Trans Tech Publications Ltd. https://doi.org/10.4028/www.scientific.net/AMM.361-363.658 
Stanford, C., Jiang, J. Q., \& Alsheyab, M. (2010). Electrochemical production of ferrate (iron VI): application to the wastewater treatment on a laboratory scale and comparison with iron (III) coagulant. Water, Air, and Soil Pollution, 209(1-4), 483-488. https://doi.org/10.1007/s11270-009-0216-4

Strosnider, W. H. J., López, F. L., LaBar, J. A., Palmer, K. J., \& Nairn, R. W. (2014). Unabated acid mine drainage from Cerro Rico de Potosí, Bolivia: uncommon constituents of concern impact the Río Pilcomayo headwaters. Environmental Earth Sciences, 71(7), 32233234. https://doi.org/10.1007/s12665-013-2734-Z

Sun, X. H., Wang, L., Li, W. C., \& Tuo, W. Q. (2013). Preparation of liquid ferrate and the optimization of process parameters. In Advanced Materials Research (Vol. 772, pp. 884-887). Trans Tech Publications Ltd. https://doi.org/10.4028/www.scientific.net/AMR.772.884

Thompson, G. W., Ockerman, L., \& Schreyer, J. M. (1951). Preparation and purification of potassium ferrate (VI). Journal of the American Chemical Society, 73(3), 1379-1381. https://doi.org/10.1021/ja01147a536

Waite, T. D., \& Gray, K. A. (1984). Oxidation and coagulation of wastewater effluent utilising ferrate (VI) ion. In Studies in Environmental Science 23, 407-420. Elsevier. https://doi.org/10.1016/S0166-1116(08)71247-0

Weissenstein, K., \& Sinkala, T. (2011). Soil pollution with heavy metals in mine environments, impact areas of mine dumps particularly of gold-and copper mining industries in Southern Africa. Arid Ecosystems, 1(1), 53-58. https://doi.org/10.1134/S2079096111010082

World Health Organization (WHO). (2017). Guidelines for drinking-water quality: the fourth edition incorporating the first addendum. License: CC BY-NC-SA 3.0 IGO. Available online at https://apps.who.int/iris/bitstream/handle/10665/254637/9789241549950eng.pdf;jsessionid=F099F3FEEEBB3C1A1A81964E06B241FC? sequence=1. Accessed on the $8^{\text {th }}$ August 2020.

Yates, B. J., Zboril, R., \& Sharma, V. K. (2014). Engineering aspects of ferrate in water and wastewater treatment: A review. Journal of Environmental Science and Health, Part A, 49(14), 1603-1614. https://doi.org/10.1080/10934529.2014.950924

Younger, P. L. (2002). Mine waste or mine voids: which is the most important long-term source of polluted mine drainage. In the United Nations Environment Program, Mineral Resources Forum: current feature paper.

Zheng, L., \& Deng, Y. (2016). Settleability and characteristics of ferrate (VI)-induced particles in advanced wastewater treatment. Water Research, 93, 172-178. https://doi.org/10.1039/C8EW00048D 